\title{
Livestock-Associated Methicillin-Resistant Staphylococcus Aureus (LA-MRSA) CC398: An Emerging Infectious Disease
}

\author{
Aswin Rafif Khairullah ${ }^{1}$, Sri Agus Sudjarwo ${ }^{2}$, Mustofa Helmi Effendi ${ }^{3 *}$, Sancaka Cashyer \\ Ramandinianto $^{4}$, Katty Hendriana Priscilia Riwu ${ }^{5}$ \\ \{aswinrafif@gmail.com ${ }^{1}$, ags158@yahoo.com ${ }^{2}$, mheffendi@yahoo.com ${ }^{3}$, sancakachasyer@yahoo.com ${ }^{4}$, \\ cattypricyllia@gmail.com $\left.{ }^{5}\right\}$ \\ Doctoral Program in Veterinary Science, Faculty of Veterinary Medicine, Universitas Airlangga, \\ Surabaya, Indonesia ${ }^{1}$, Department of Veterinary Pharmacology, Faculty of Veterinary Medicine, \\ Universitas Airlangga, Surabaya, Indonesia ${ }^{2}$ Department of Veterinary Public Health, Faculty of \\ Veterinary Medicine, Universitas Airlangga, Surabaya, Indonesia ${ }^{3}$ Master Program in Veterinary Disease \\ and Public Health, Faculty of Veterinary Medicine, Universitas Airlangga, Surabaya, Indonesia ${ }^{4}$
}

\begin{abstract}
Livestock-associated methicillin-resistant Staphylococcus aureus (LA-MRSA) is a pathogenic bacterial strain that can infect livestock, pets and humans. LA-MRSA was identified for the first time in 2005 where the new MRSA clone of sequence type 398 (ST398) was grouped and identified in the clone complex 398 (CC398). Cases of LAMRSA CC398 infection began to be reported frequently in the next few years. From 2000 onwards, case reports of LA-MRSA CC398 infection are becoming more frequent. LAMRSA CC398 transmission to the host is generally mediated by physical contact with livestock, but also through contaminated dust. LA-MRSA CC398 has the same virulence potential as Staphylococcus aureus found in humans and is generally associated with the same clinical features. Rapid detection of LA-MRSA examination can be done with a nasal swab, it is very important to adequately identify individuals who have been infected with LA-MRSA and molecular detection of LA-MRSA CC398 using polymerase chain reaction (PCR). Several other antibiotics such as linezolid, telavancin, daptomycin, tedizoid, dalbavancin, oritavancin, ceftobiprole, and ceftaroline have been developed and approved for the treatment of the LA-MRSA CC398 infection. Interventions that need to be done to prevent transmission and infection of LA-MRSA CC398 include screening, isolation of contacts, hand hygiene, cohorts, and decolonization as additional standard precautions.
\end{abstract}

Keywords: LA-MRSA; CC398; Emerging Infectious Disease

\section{Introduction}

Livestock-associated methicillin-resistant Staphylococcus aureus (LA-MRSA) was first identified in 2005 [1] in which the new MRSA clone of sequence type 398 (ST398) was grouped and identified in the clone complex 398 (CC398). The term LA-MRSA CC398, which originally appeared in pigs in Europe in 2005, has also been found in other livestock species in various European countries and in North America [1-5]. The spread of LA-MRSA is very common in livestock environments and can cause fatal cases of infection in animals and even humans, so that LA-MRSA is a pathogenic bacterial strain that is dangerous to the health of livestock and humans $[6,7]$. However, the cases of human disease caused by LA-MRSA infection are lower 
than that of other MRSA strains (such as CA-MRSA and HA-MRSA) possibly because LAMRSA infected patients show different demographic conditions because they live in a farm environment and only a short stay in the hospital, the clinical symptoms of patients infected with LA-MRSA CC398 are usually mild and not severe [8], so that cases of LA-MRSA CC398 infection still receive less serious attention from the public than other strains of Staphylococcus aureus [9]. In fact, LA-MRSA is a strain of Staphylococcus aureus which has become an emerging infectious disease worldwide [10].

Several previous studies have been conducted, showing the result that there has been a rapid increase in the number of people infected with LA-MRSA CC398 in recent years. Not everyone infected with LA-MRSA CC398 has had direct contact with livestock [11, 12]. The incidence of LA-MRSA CC398 invasive infection has also increased sharply and peaked in 2014 in the European region $[13,14]$.

LA-MRSA CC398 associated with soft tissue and skin infections can affect healthy and young farmers, but LA-MRSA transmission can also occur in the human population, which includes elderly people and people with immune disorders at risk of exposure to LA disease. LA-MRSA is invasive [11]. In the last ten years the strain of LA-MRSA CC398 can cause zoonotic disease cases in humans and has now become a major problem in public health in the world [15]. The purpose of writing this review is to explain the general definition, description, emergence, epidemiology, transmission, infection, diagnostic detection, the public health consequences, treatment, and prevention of LA-MRSA.

\section{Methodology}

\subsection{General definition of LA-MRSA}

Livestock-associated methicillin resistant Staphylococcus aureus (LA-MRSA) is a pathogenic bacterial strain that can contaminate livestock, pets and humans. MRSA cases in livestock were first informed in 1972 in cases of dairy cattle with mastitis in Belgium, where at that time MRSA cases were usually found in humans [16]. Since then, cases of MRSA in livestock have been reported in many European countries [17]. In 2005 [1] a new lineage of MRSA with sequence type 398 (ST398) was identified in the clone complex 398 (CC398) which began to be called LA-MRSA CC398 and capable of infecting human. In addition, LA-MRSA CC398 has also been informed globally in horses, pigs, poultry, and cattle [18].

\subsection{LA-MRSA colonal complex 398 (CC398)}

LA-MRSA CC398 is a major clonal complex that is widely identified in North America and Europe. It has occasionally been identified in Asia [19] and has also been identified in Africa $[20,21]$. This clonal complex is associated primarily with the incidence of LA-MRSA infection in pigs and calves [17, 22-27]. LA-MRSA isolate CC398 has rarely been identified in poultry [28] and horses [29, 30]. All genome sequencing has shown that the CC398 clonal complex is of human origin [15], indeed in humans the case of LA-MRSA CC398 infection still occurs primarily as methicillin-susceptible Staphylococcus aureus (MSSA) [31-34], although it has a low prevalence. MSSA CC398 has also been detected in animals such as pigs [35], dogs [36], cattle [32], and poultry [32, 37].

Currently LA-MRSA CC398 has 43 types of genome sequences [38], but in pigs the main genome sequence is ST398. Other types of sequences (ST) found in pigs are ST1968, ST1967, 
ST1966, ST1965, and ST541 [39-41]. However, previous studies have indicated that there is a certain subgroup of the ST398 strain in humans, but different from LA-MRSA ST398 [42], which can be easily distinguished by detection of Single Nucleotide Polymorphism (SNP), and the appearance of scn and tet (M). [43]. The results of a study conducted in the Netherlands reported that all CC398 strains found there were LA-MRSA [12]. However, the prevalence rate of LA-MRSA CC398 infection continues to increase in various countries, even though each country has different geographical conditions [44-46].

LA-MRSA CC398 is not considered to be highly pathogenic in humans. Whereas in animals, LA-MRSA CC398 was involved in cases of bovine mastitis [25, 47-50] and arthritis of the legs in turkeys [37]. There is still little information about LA-MRSA CC398 in pigs because the main type of pathogen frequently found in pigs is Staphylococcus hyicus [51], although Staphylococcus aureus can still be found from lesions in pigs [51]. However, recent reports suggest that LA-MRSA CC398 infection is more prevalent in pigs and humans than previously thought [52-54], but this study requires further research.

\subsection{Emergence of LA-MRSA}

From 1970 to 2000, MRSA strains were rarely dissociated from animals, especially livestock, because MRSA strains are usually found only in humans, as indicated by bio-typing. So that until the end of the $20^{\text {th }}$ century, it was estimated that the reservoir in livestock was not associated with MRSA which causes disease in humans. It is believed that cases of MRSA infection are a problem that occurs due to the misuse of antibiotics in human medicine [55]. In 1972 it was reported for the first time a case of MRSA infection was isolated from a dairy cow with mastitis [56]. Then cases of this infection began to be reported several times in the next 28 years. From 2000 onwards, case reports of LA-MRSA infection have become more frequent, in 2007 there were reports of MRSA (ST1; spa-type) transmission between cow and humans [57]. The first case of LA-MRSA infection in humans was reported in 2005 in a girl who was hospitalized for six months in the Netherlands.

The girl was still detected positive for LA-MRSA despite various treatment attempts. Both of the girl's parents apparently lived in a pig farm area and both of the girl's parents were also infected with LA-MRSA [1]. LA-MRSA cannot be categorized by standard pulsed-field gel electrophoresis (PFGE), then it is further accessed to regional LA-MRSA reservoirs and pig farmers [58]. A study of LA-MRSA in pigs in Slaughterhouses (RPH) showed that LA-MRSA was widely distributed among pigs in the Netherlands [59].

The genotype examination showed that the LA-MRSA strain isolated from pigs and hog breeders could not be categorized as standard PFGE because this strain was resistant to digestion of the SmaI enzyme that is used routinely, therefore it is called asnon-typeable. MRSA (NTMRSA). Subsequent studies have shown that the LA-MRSA strain can be typed if other enzymes are used [60]. The LA-MRSA strain has clonal complex 398 (CC398), with most LAMRSA having sequence type 398 (ST398). The risk factor for humans being exposed to LAMRSA is if they are on cattle and pig farms [61]. From 2005 onwards, more cases of LA-MRSA infection were reported in different livestock such as cattle [25], pigs [58, 62], and poultry [63, 64], occurring in European countries [65], as well as in America [3] and Asia [66, 67].

The baseline EU-study relates to the prevalence of LA-MRSA in the pig industry in most European countries, indicating that LA-MRSA infections are common in pig farms. It is different from studies in Europe and America, LA-MRSA ST398 does not seem to be the dominant strain of MRSA in pig farms in Asia. Several previous studies have shown that the dominant LA-MRSA strain in pig farms in Asia is sequence type 9 (ST9) [66-68]. Meanwhile ST72 is the dominant LA-MRSA strain found in meat products in Korea [69, 70]. 
The LA-MRSA strain has also been detected in domestic animals, but this type of LA-MRSA is generally different from that of livestock. The underlying reason is that there is a transmission route thought to be from humans to pets, therefore the LA-MRSA strain in humans may also be found in domesticated animals [71].

\subsection{Epidemiology of LA-MRSA}

In the early $21^{\text {st }}$ century, to be precise in 2005, the LA-MRSA strain isolated from pigs was identified with sequence type 398 (ST398) and then the strains were associated and grouped collectively into clone complex 398 (CC398) [72]. LA-MRSA CC398 was first detected in pigs and breeders, then since then LA-MRSA has been detected in other livestock (cattle, poultry), pets (dogs), and humans in several European states, Australia, North America, Asia, and South America. This finding of the LA-MRSA CC398 strain led to an increased incidence of livestockrelated MRSA, when there had previously been the incidence of hospital-acquired MRSA infection (HA-MRSA) and community-acquired MRSA infection (CA-MRSA) [72].

CC398 is the type of LA-MRSA most identified in most European countries [72-75], so that most people assume that the terms CC398 and LA-MRSA are practically interchangeable. However, while the LA-MRSA CC398 strain has been detected in worldwide, livestock-related epidemiology of Staphylococcus aureus has been identified as distinct in other geographic areas. Several studies that have been carried out in Asia have shown that the LA-MRSA ST9 strain is the LA-MRSA type that is most often found in several Asian countries [67, 76-79]. In poultry there was also the LA-MRSA CC398 strain [28, 37, 80] but other types of LA-MRSA were also found that were not related to LA-MRSA CC398, one of which was LA-MRSA CC5 [37, 81] or other types [28]. In North America, a greater diversity of livestock-related Staphylococcus aureus has been found than is found in Asia or Europe, with reports of LA-MRSA CC398 infection as well as various other strains of Staphylococcus aureus in live animals.

The epidemiology of LA-MRSA CC398 and other types of LA-MRSA that have been detected in humans and animals [67] has led to the idea that further investigations of LA-MRSA CC398 in the host appear to be related to animals and humans and can lead to active cases of sympathetic infection in both species [62, 82]. Further studies, LA-MRSA CC398 and LAMRSA CC5 isolated from poultry have been photogenically analyzed and have shown that transmission originates from humans, transmitting the LA-MRSA strain to animals, then these strains spread and evolve so that they can carry out various adaptations to animal's host [15, 83]. Therefore, the LA-MRSA CC398 strain associated with both livestock and humans is a complex study or association in the host based solely on the type of sequence.

\subsection{Transmission of LA-MRSA}

Staphylococcus aureus transmission to the host is generally mediated by physical contact. The condition of dusty cattle sheds is also prone to LA-MRSA transmission [84]. So there is a possibility that the case of LA-MRSA infection in farmers occurs through inhalation of dust that has been contaminated by LA-MRSA [85]. On nasal swab examinations, as many as 77-86\% of farmers working in the stable test positive for LA-MRSA [86, 87]. The degree of LA-MRSA colonization appears to depend on the intensity of direct contact with the animal and the duration of exposure [88]. When the farmer is on vacation or is not active in the cage, LA-MRSA colonization continues even though there is no farmer exposure [89, 90]. Meanwhile, people who live near farms are less likely to be exposed to LA-MRSA, with a prevalence of 4-5\% [86].

In comparative longitudinal studies conducted in Denmark, Belgium, and the Netherlands, it was stated that the intensity of contact with livestock was a major contributing factor for LAMRSA transmission among members of the farmer family (Denmark 0\%, Belgium 29\%, and 
the Netherlands $6 \%$ ). The increased rate of LA-MRSA transmission observed among family members from Belgium appears to be related to country-specific differences in exposure to livestock [91]. Another study conducted in the Netherlands revealed that direct contact with livestock and breeders who have been infected with LA-MRSA is a major factor in the transmission of LA-MRSA transmission between members of the breeder family [92].

In the Netherlands, a national program to reduce the use of antibiotics in livestock began in 2010. In Germany a longitudinal study revealed that LA-MRSA colonization in farm animals, humans who are active in livestock pens occurred due to a $44 \%$ reduction in antibiotic use in livestock. Livestock is associated with decreased LA-MRSA prevalence in livestock and humans, regardless of farm animal contact [93]. In Taiwan, the results of isolation from pig nose swabs showed a higher prevalence of LA-MRSA ST9 on large-scale farms (34\%) compared to those on small-scale farms (7\%), this is reflected by the level of intensity of direct human contact with pigs, which in large-scale farms has a higher intensity (36.8\%) than on small-scale farms (9.1\%) [79].

LA-MRSA colonization was also observed from nasal swabs of slaughterhouse workers [64, 94], also in veterinarians in Germany [87, 95], and in veterinarians in Belgium [96], where the presence of a veterinarian is also a factor one of the main risk factors. Veterinarians' family members may also contract LA-MRSA [86, 97]. Sequencing of the whole genome map for LAMRSA colonization among veterinary families suggests the possibility that LA-MRSA transmission may occur between humans [98]. In studies in conventional agriculture, LAMRSA CC398 was not found in livestock and humans in German organic farms [99], and less frequently found in livestock in organic farming compared to conventional farms in the Netherlands [100]. It is extremely rare for LA-MRSA to spread among humans outside of farms, as was the case in a study in Germany which had a high density of pig farms in northwestern Germany [86].

But in addition, based on the results of screening for hospitalized patients, the prevalence of LA-MRSA in northwest Germany is much higher than in the rest of Germany [101]. This is consistent with a study conducted in the Netherlands, where livestock density was identified as a major risk factor for the transmission of LA-MRSA transmission [102].

Recent studies have shown LA-MRSA emissions in the air free of livestock pens and have been found in the air up to 350 meters above pens and as far as 500 meters above ground level of pens [103]. LA-MRSA has also been identified in livestock manure from chicken farms and has also been identified in soils treated with manure from livestock manure [104]. In this study, the appearance of LA-MRSA in stool samples in Austria is an interesting matter to be investigated [105]. It needs further explanation that humans who live in close proximity to conventional farms will be at risk of being infected with LA-MRSA. A study in Lower Saxony in Germany revealed that LA-MRSA colonization was found in about $1 \%$ of the humans living adjacent to the farm site [106].

In the results of an epidemiological study in Pennsylvania, United States, where cases of skin and soft tissue infections by LA-MRSA were more common in humans who lived near fields that were given manure. However, research in this sector is still limited due to the lack of data on the amount of LA-MRSA in livestock manure and human waste [107]. Whereas LAMRSA which is identified in pets such as dogs and cats will have the potential for transmission to humans, therefore it is necessary to remember the importance of maintaining the cleanliness of the house and cage [108].

It can be assumed that human-to-human transmission of LA-MRSA CC398 transmission is rare. However, there are recent studies from Spain [109] and from Germany [110] regarding LA-MRSA infection in humans despite no history of contact with livestock. It was observed in 
the Netherlands in $15 \%$ of all cases of LA-MRSA CC398 infection in some humans is all of these humans had no direct contact with cows and pigs [12].

Apart from animal-to-human, human-to-human, LA-MRSA environmental and transmission exposure, LA-MRSA strains can also be found in contaminated livestock meat products. This can be very risk in humans who are accustomed to eating livestock, a study in the Netherlands revealed that people who regularly consume poultry are at increased risk of being infected with LA-MRSA [111].

\subsection{Infection of LA-MRSA}

LA-MRSA CC398 has the same virulence potential as Staphylococcus aureus found in humans and is generally associated with the same clinical features. In hospital patients infected with LA-MRSA CC398 have symptoms of skin and soft tissue infections requiring surgical intervention. LA-MRSA infected patients are usually people who have direct contact with farm animals and frequently visit livestock pens. LA-MRSA CC 398 represents about $13 \%$ of cases of severe skin and soft tissue infections resulting from being infected with LA-MRSA CC398 [112]. The incidence of LA-MRSA infection is rare in Germany so it is not known.

LA-MRSA CC398 infection can spread to the hospital through patients suffering from LAMRSA CC398 infection who are in need of intensive care and patients who have LA-MRSA colonization of the nose. This spread of LA-MRSA can lead to nosocomial infections such as infection after joint arthroplasty, infection at the surgical site, septicemia, and ventilator-related pneumonia [14, 113]. A study of LA-MRSA CC398 colonization in the Brandenburg hospital, southern Germany, a region with a low livestock density, reported an LA-MRSA CC398 colonization of $0.08 \%$ of the 13,855 individuals studied [114]. In the Ems-Dollart region of the state of North Rhine Westphalia which has a high livestock density, the proportion of LAMRSA CC398 among all MRSA strains identified in hospitalized patients (LA-MRSA CC398 detected $1.6 \%$ of all infected individuals studied) increased from $14 \%$ in 2008 to $23 \%$ in 2011.

Meanwhile, in line with the proportion of LA-MRSA CC398 among all identified MRSA types, there were cases of wound infection which increased from 7\% in 2008 to $10 \%$ in 2011 [102]. The proportion of LA-MRSA CC398 among all MRSA strains that have been identified as having septicemia in this region is about $10 \%$, while it is still substantially lower $(1.8 \%)$ in all regions of North Rhine Westphalia [115], which corresponds to that proportion has been reported throughout Germany [112]. The proportion of LA-MRSA CC398 among all MRSA strains of infection and colonization in humans should be investigated in relation to overall MRSA prevalence. This is due to the possibility that there is a high prevalence of cases of LAMRSA CC398 infection in countries that have a low prevalence of HA-MRSA, such as in the Netherlands of all the patients screened at admission to the hospital there were $9.7 \%$ positive MRSA of all individuals, of these positive MRSA numbers, it was found that $78 \%$ were LAMRSA CC398 infection and 22\% were non-LA-MRSA [116].

Human-to-human infection of LA-MRSA CC398 in the hospital is still rarely observed [117], because LA-MRSA CC398 infection is very rare in hospital compared to HA-MRSA infection [118]. LA-MRSA CC398 infection may occur in the hospital, as demonstrated in all genome sequencing-based phylogenetic analyzes for subclade obtained from environmental isolates and newborns in Scottish hospitals [119]. In cases of LA-MRSA CC398 infection requiring antibiotic therapy, the antibiotic resistance profile of LA-MRSA CC398 has varied resistance and sensitivity. Usually LA-MRSA CC398 is resistant to $\beta$-lactam antibiotics, glycosamides, macrolides, tetracyclines, streptogramin, and some fluoroquinolones and cotrimoxazole. 
The LA-MRSA CC398 strain is still sensitive to glycopeptide antibiotics, tigecycline, daptomycin, fosfomycin and fusidic acid, and some exceptions to linezolid. Therapy using linezolid requires high awareness of the patient's health. In addition to ribosomal protein mutations and $23 \mathrm{~S}$ rRNA, linezolid resistance can be transferred with plasmid activity storing the transferable cfr gene that mediates multi-resistance to linezolid, fenicol, lincosamides, and pleuromutilin by methylated by $23 \mathrm{~S}$ rRNA in human medicine [120]. Thus, selective pressure that supports spread can be provided in treatment using linezolid in humans, as well as thiamulin and florfenicol in veterinary medicine [121].

The cfr gene was isolated for the first time in coagulase-negative Staphylococcus from livestock in Europe [122] and has recently been reported in China [123]. In general, linezolid resistance is still rare in staphylococcus coagulase (CNS) that infects humans [124], but a group of nosocomial infections in Staphylococcus epidermidis containing the cfr gene [125] has been reported. Only a single LA-MRSA CC398 isolate containing the cfr gene has been found in livestock in Europe [126], but cases of this infection are more frequently reported in China [123]. Linezolid resistance is still rare in MRSA isolated from humans [127]. There has only been one report of a human isolate resistant to linezolid, apart from the emergence of a HAMRSA epidemic containing the cfr gene in a Madrid hospital [128].

\subsection{Rapid clinical detection of LA-MRSA}

Rapid detection of LA-MRSA tests can be performed with a nasal swab, it is very important to adequately identify individuals who have been infected with LA-MRSA and can be given appropriate infection control immediately. In addition, the rapid detection of LAMRSA examination from clinical samples of patients can also help optimize the care of patients who have been infected with LA-MRSA. The clinical problem that often occurs is that patients experience sepsis and are found to have clustered Gram-positive cocci in the blood (GPCCL). It is likely the highly pathogenic organism Staphylococcus aureus or Staphylococcus coagulase (CNS). CNS contributes 60\% -80\% [129, 130] of GPCCL isolates in blood and prosthetic materials, contamination that occurs in blood is usually initiated by LA-MRSA colonization through the surface of the injured skin. With this, it is necessary to have high accuracy in rapid detection to differentiate CNS and Staphylococcus aureus [130].

After it was confirmed that Staphylococcus aureus was found, there were still further clinical problems whether this was MSSA or MRSA. These patients are usually given broadspectrum antibiotic therapy until the susceptibility of new organisms is fully established 24 hours later after antibiotic administration. If the doctor gives empiric antibiotics for MSSA to a patient infected with LA-MRSA, there will be an increased risk of death in the patient, and vice versa. A number of studies have revealed that antimicrobials that target LA-MRSA infection, such as vancomycin, produce sustained bacteremia and a higher risk of death than $\beta$-lactams used to treat MSSA therapy, such as cloxacillin [131].

In one retrospective study looking at MSSA bacteremia in drug users, the risk of death was $39.4 \%$ in vancomycin-treated patients, but only $11.4 \%$ in flucloxacillin-treated patients. In the subgroup of patients treated with vancomycin for 48 hours to wait for outcome susceptibility occurred a mortality of $40 \%$, of which incidence suggests that empiric antibiotic treatment had a major impact on clinical outcome [132]. Because it is necessary to do a quick detection to distinguish MSSA and MRSA with a high degree of accuracy.

Several prospective studies have been conducted to analyze the usefulness of rapid diagnostic tests for the detection of LA-MRSA and its impact on antibiotic prescribing. Implementation of rapid diagnostic testing will result in timely, effective therapy, significantly reducing hospital costs and length of stay $[133,134]$. In comparison, the adjustment time 
referred to as a turnaround time (TAT) on the BD GeneOhm ${ }^{\mathrm{TM}}$ StaphSR Assay was 13.2-21.6 hours shorter than chromogenic media, namely 46.2-79.2 hours in detecting LA-MRSA [135]. Rapid detection of LA-MRSA resulted in a $21 \%$ reduction in overall patients treated with antiMRSA antibiotics.

On the other hand, among patients with negative blood culture (BC) for Staphylococcus aureus, the mean duration of antibiotic therapy was reduced from 19.7 hours to 12.2 hours and there was a reduction in the mean 6.2 days of hospital stay in patient's hospital. In the implementation of rapid molecular detection, the optimal treatment time would decrease to 44.638.4 hours among patients with the MSSA bacteremia [136, 137]. With this, the rapid detection of LA-MRSA will have a direct impact on infection control and patient care.

\subsection{Molecular detection of LA-MRSA}

LA-MRSA CC398 is encoded by the mec $\mathrm{A}$ and mec $\mathrm{C}$ coding genes located on the mobile genetic element of the mec cassette chromosome chromosome (SCCmec). To date, there are at least 11 types of SCCmec (I-IX) and are accompanied by many subtypes (IVa, IVb, IVc, IVd, IVg, and IVh) in the LA-MRSA CC398 strain [138, 139]. Molecular detection of LA-MRSA requires target-specific detection of Staphylococcus aureus with the $n u c, g y r \mathrm{~B}$, or Staphylococcus A protein gene, coupled with the identification of LA-MRSA with the genes encoding femA, mecA, mecC, or SSCmec-orfX [140-143]. So those different kits are needed in molecular detection of LA-MRSA CC398 using polymerase chain reaction (PCR). However, the emergence of the mec variant on LA-MRSA CC398 suggests that the specific target for the detection of LA-MRSA CC398 needs to be continuously re-evaluated.

\subsection{Public Health Consequences of LA-MRSA}

Humans who have had direct contact with LA-MRSA positive animals will have a higher risk of contracting LA-MRSA. It has also been reported in humans who work in horse stables, veterinary clinics, and livestock environments [71]. It has been reported that LA-MRSA CC398 has limited host specificity, however this strain can colonize and cause cases of infection in multiple hosts. To date, the mechanism of host adaptation to LA-MRSA CC398 infection is poorly known [144]. It is of concern that LA-MRSA CC398 infection can cause infection and serious (invasive) outbreaks [145].

There is a potential risk of introducing LA-MRSA CC398 from livestock as a reservoir to the hospital via humans as a vector. Therefore, in the Netherlands, cattle and hog farmers are classified as a risk group as defined by the "Search and Destroy" policy. As a result, the number of patients admitted to hospital with suspected LA-MRSA CC398 colonization and requiring MRSA screening has increased in the Netherlands. This is a major problem for the health care system in hospitals [146].

Identification of factors and knowledge of LA-MRSA CC398 infecting humans is very important in the success of the "Search and Destroy" policy. A proper understanding of the mechanisms underlying the transmission and exposure of LA-MRSA CC398 in livestock and humans can have a significant impact on antibiotic therapy policy and infection control in the hospital. It also provides information for evidence-based guidance regarding the development of new measures and strategies for the control and prevention of LA-MRSA CC398 infection [147]. 


\subsection{Treatment of LA-MRSA}

The emergence of methicillin resistance was accompanied by the development of resistance of Staphylococcus aureus to most of the non- $\beta$-lactam antibiotics and led to reduced options for treating cases of infection caused by LA-MRSA CC398. In the 1980s, several LAMRSA strains were resistant to all available antibiotics except vancomycin [148, 149]. This situation was exacerbated by the emergence of strains of Staphylococcus aureus which became insensitive to vancomycin in the late 1990s [150], along with vancomycin-resistant strains of Staphylococcus aureus (MIC: $\geq 32 \mathrm{mg} / \mathrm{L}$ ) in the United States and other countries [149].

Vancomycin-resistant Staphylococcus aureus may acquire the vanA gene complex from vancomycin-resistant enterococci, whereas vancomycin-resistant Staphylococcus aureus intermediate is due to the thickening of the bacterial cell wall and is able to bind vancomycin thereby reducing diffusion into cells [151]. This development led to the selection of new antibiotic alternatives that have activity against LA-MRSA CC398. Furthermore, several other antibiotics such as linezolid, telavancin, daptomycin, tedizoid, dalbavancin, oritavancin, ceftobiprole, and ceftaroline have been developed and approved for clinical treatment.

\subsection{Prevention of LA-MRSA infection}

The number of pathogenic bacteria that are resistant to several antibiotics such as LAMRSA CC398 continues to increase globally in health care facilities and in the community [152]. The emergence of multi-antibiotic resistant strains of LA-MRSA has reduced options for treatment caused by LA-MRSA infection. From this incident, research and discovery of antibacterial agents were carried out to overcome these problems.

However, the multi-antibiotic resistant LA-MRSA strains have wide variations in their temporal and geographic distribution. LA-MRSA strains resistant to multiple antibiotics also vary in their virulence and epidemic capacity. The factors that mediate the transmission of transmission in health care facilities are not well known. On the other hand, there is a serious threat if there is resistance to newly developed antimicrobial agents, therefore it is necessary to implement other methods to limit the spread of pathogens that are resistant to various antibiotics. Some of the strategic steps taken are active surveillance of resistant LA-MRSA pathogens, supervision of antibiotic therapy, and better infection control methods [152].

Infection prevention measures will reduce the risk of transmission of multi-antibiotic resistant LA-MRSA in health care settings [153] and reduce the medical costs incurred by LAMRSA infection [154]. Interventions that need to be taken to prevent LA-MRSA transmission and infection include screening, contact isolation, hand hygiene, cohorts, and decolonization as additional standard precautions. This procedure should be continued until the patient is tested negative for LA-MRSA which is resistant to various antibiotics.

\section{Conclusion}

LA-MRSA has been identified in livestock, mostly in cattle and pigs. However, other animals such as poultry and domestic animals are infected with LA-MRSA, because this strain can be transmitted to other animal species and humans. Like other pathogenic bacteria, LAMRSA can adapt to new hosts and produce toxins. It has been identified that the most common LA-MRSA clone complex is CC398. It has been reported that humans who have had direct contact with LA-MRSA positive livestock are at risk of being infected with LA-MRSA. Monitoring of frequent cases of LA-MRSA infection in livestock and humans is necessary to 
observe changes in the epidemiology and to determine strategies for effective LA-MRSA infection control measures.

\section{References}

[1] Voss A, Loeffen F, Bakker J, Klaassen C, Wulf M. Methicillin-resistant Staphylococcus aureus in pig farming. Emerg Infect Dis. 2005; 11: 1965-6.

[2] Khanna T, Friendship R, Dewey C, Weese JS. Methicillin-resistant Staphylococcus aureus colonization in pigs and pig farmers. Vet Microbiol. 2008; 128, 298-303.

[3] Smith TC, Male MJ, Harper AL, Kroeger JS, Tinkler GP, Moritz ED, et al. Methicillin-resistant Staphylococcus aureus (MRSA) strain ST398 is present in midwestern U.S. swine and swine workers. PLoS One. 2009; 4: e4258.

[4] Smith TC, Gebreyes WA, Abley MJ, Harper AL, Forshey BM, Male MJ, et al. Methicillinresistant Staphylococcus aureus in pigs and farm workers on conventional and antibiotic-free swine farms in the USA. PLoS One. 2013; 8: e63704.

[5] Goerge T, Lorenz MB, van Alen S, Hubner NO, Becker K, Kock R. MRSA colonization and infection among persons with occupational livestock exposure in Europe: prevalence, preventive options and evidence. Vet Microbiol. 2017; 200: 6-12.

[6] Bradley SF. Eradication or decolonization of methicillin-resistant Staphylococcus aureus carriage: what are we doing and why are we doing it? Clin Infect Dis. 2007; 44: 186-9.

[7] Cuny C, Wieler LH, Witte W. Livestock-Associated MRSA: The Impact on Humans. Antibiotics. 2015; 4: 521-43.

[8] Becker K, Ballhausen B, Kahl BC, Kock R. The clinical impact of livestock-associated methicillin-resistant Staphylococcus aureus of the clonal complex 398 for humans. Vet Microbiol. 2017; 200: 33-38.

[9] Cuny C, Kock R, Witte W. Livestock associated MRSA (LA-MRSA) and its relevance for humans in Germany. Int J Med Microbiol. 2013; 303: 331-7.

[10] Smith TC. Livestock-associated Staphylococcus aureus: the United States experience. PLoS Pathog. 2015; 11: e1004564.

[11] Larsen J, Petersen A, Sørum M, Stegger M, van Alphen L, Valentiner-Branth P, et al. Methicillin-resistant Staphylococcus aureus CC398 is an increasing cause of disease in people with no livestock contact in Denmark, 1999 to 2011. Euro Surveill. 2015; 20(37).

[12] Lekkerkerk WSN, van Wamel WJB, Snijders SV, Willems RJ, van Duijkeren E, Broens EM, et al. What is the origin of livestock-associated methicillin-resistant Staphylococcus aureus clonal complex 398 isolates from humans without livestock contact? An epidemiological and genetic analysis. J Clin Microbiol. 2015; 53: 1836-41.

[13] Larsen J, Petersen A, Larsen AR, Sieber RN, Stegger M, Koch A, et al. Emergence of livestockassociated methicillin-resistant Staphylococcus aureus bloodstream Figure 1. Arrow's infections in Denmark. Clin Infect Dis. 2017; 65(7): 1072-6.

[14] van Cleef BA, Monnet DL, Voss A, Krziwanek K, Allerberger F, Struelens M, et al. Livestockassociated methicillin-resistant Staphylococcus aureus in humans. Europe. Emerg Infect Dis. 2011; 17:502-5.

[15] Price LB, Stegger M, Hasman H, Aziz M, Larsen J, Andersen PS, et al. Staphylococcus aureus CC398: host adaptation and emergence of methicillin resistance in livestock. mBio. 2012; 3(1) : 305-11.

[16] Devriese LA, Van Damme LR, Fameree L. Methicillin (cloxacillin)-resistant Staphylococcus aureus strains isolated from bovine mastitis cases. Zentralbl Veterinärmed. 1972; 19: 598-605.

[17] Crombé F, Argudín MA, Vanderhaeghen W, Hermans K, Haesebrouck F, Butaye P. Transmission dynamics of methicillin-resistant Staphylococcus aureus in Pigs Front Microbiol. 2013; 4: 57.

[18] Butaye P, Argudin MA, Smith TC. Livestock-associated MRSA and its current evolution. Curr Clin Micro Rpt. 2016; 3: 19-31. 
[19] Chuang YY, Huang YC. Livestock-associated meticillin-resistant Staphylococcus aureus in Asia: an emerging issue? Int J Antimicrob Agents. 2015; 45: 334-40.

[20] Abdulgader SM, Shittu AO, Nicol MP, Kaba M. Molecular epidemiology of Methicillinresistant Staphylococcus aureus in Africa: a systematic review. Front Microbiol. 2015; 6: 348.

[21] Chairat S, Gharsa H, Lozano C, Gomez-Sanz E, Gomez P, Zarazaga M, et al. Characterization of Staphylococcus aureus from raw meat samples in Tunisia: detection of clonal lineage ST398 from the African continent. Foodborne Pathog Dis. 2015; 12: 686-92.

[22] Peeters LE, Argudín MA, Azadikhah S, Butaye P. Antimicrobial resistance and population structure of Staphylococcus aureus recovered from pigs farms. Vet Microbiol. 2015; 180: 151 6.

[23] Crombé F, Willems G, Dispas M, Hallin M, Denis O, Suetens C, et al. Prevalence and antimicrobial susceptibility of methicillin-resistant Staphylococcus aureus among pigs in Belgium. Microb Drug Resist. 2012; 18: 125-31.

[24] Nemeghaire S, Argudín MA, Haesebrouck F, Butaye P. Epidemiology and molecular characterization of methicillin-resistant Staphylococcus aureus nasal carriage isolates from bovines. BMC Vet Res. 2014; 10: 153.

[25] Vanderhaeghen W, Cerpentier T, Adriaensen C, Vicca J, Hermans K, Butaye P. Methicillinresistant Staphylococcus aureus (MRSA) ST398 associated with clinical and subclinical mastitis in Belgian cows. Vet Microbiol. 2010; 144: 166-71.

[26] Verhegghe M, Pletinckx LJ, Crombé F, Vandermissen T, Haesebrouck F, Butaye P, et al. Methicillin-resistant Staphylococcus aureus (MRSA) ST398 in pig farms and multispecies farms. Zoonoses Public Health. 2013; 60: 366-74.

[27] Verhegghe M, Crombé F, Pletinckx LJ, Haesebrouck F, Butaye P, Herman L, et al. Genetic diversity of livestock-associated MRSA isolates obtained from piglets from farrowing until slaughter age on four farrow-to-finish farms. Vet Res. 2014; 45: 89.

[28] Nemeghaire S, Roelandt S, Argudín MA, Haesebrouck F, Butaye P. Characterization of methicillin-resistant Staphylococcus aureus from healthy carrier chickens. Avian Pathol. 2013; 42: 342-6.

[29] Van den Eede A, Martens A, Feryn I, Vanderhaeghen W, Lipinska U, Gasthuys F, et al. Low MRSA prevalence in horses at farm level. BMC Vet Res. 2012; 8: 213.

[30] Van den Eede A, Hermans K, Van den Abeele A, Flore K, Dewulf J, Vanderhaeghen W, et al. The nasal vestibulum is the optimal sampling site for MRSA screening in hospitalised horses. Vet J. 2013; 197: 415-9.

[31] Lozano C, Rezusta A, Gómez P, Gómez-Sanz E, Baez N, Martin-Saco G, et al. High prevalence of spa types associated with the clonal lineage CC398 among tetracycline-resistant methicillinresistant Staphylococcus aureus strains in a Spanish hospital. J Antimicrob Chemother. 2012; 67: 330-4.

[32] Vandendriessche S, Vanderhaeghen W, Larsen J, de Mendonca R, Hallin M, Butaye P, et al. High genetic diversity of methicillin-susceptible Staphylococcus aureus (MSSA) from humans and animals on livestock farms and presence of SCC mec remnant DNA in MSSA CC398. J Antimicrob Chemother. 2014; 69: 355-62.

[33] Benito D, Aspiroz C, Gilaberte Y, Sanmartin R, Hernandez-Martin A, Alonso M, et al. Genetic lineages and antimicrobial resistance genotypes in Staphylococcus aureus from children with atopic dermatitis: detection of clonal complexes CC1, CC97 and CC398. J Chemother. 2015; 1: $1-8$.

[34] Uhlemann AC, Dumortier C, Hafer C, Taylor BS, Sanchez J, Rodriguez-Taveras C, et al. Molecular characterization of Staphylococcus aureus from outpatients in the Caribbean reveals the presence of pandemic clones. Eur J Clin Microbiol Infect Dis. 2012; 31: 505-11.

[35] Hasman H, Moodley A, Guardabassi L, Stegger M, Skov RL, Aarestrup FM. Spa type distribution in Staphylococcus aureus originating from pigs, cattle and poultry. Vet Microbiol. 2010;141:326-31.

[36] Gómez-Sanz E, Torres C, Benito D, Lozano C, Zarazaga M. Animal and human Staphylococcus aureus associated clonal lineages and high rate of Staphylococcus pseudintermedius novel 
lineages in Spanish kennel dogs: predominance of Staphylococcus aureus ST398. Vet Microbiol. 2013; 166: 580-90.

[37] Argudín MA, Cariou N, Salandre O, Le Guennec J, Nemeghaire S, Butaye P. Genotyping and antimicrobial resistance of Staphylococcus aureus isolates from diseased turkeys. Avian Pathol. 2013; 42: 572-80.

[38] Stegger M, Aziz M, Chroboczek T, Price LB, Ronco T, Kiil K, et al. Genome analysis of Staphylococcus aureus ST291, a double locus variant of ST398, reveals a distinct genetic lineage. PLoS ONE. 2013; 8: e63008.

[39] Lim SK, Nam HM, Jang GC, Lee HS, Jung SC, Kwak HS, et al. The first detection of methicillinresistant Staphylococcus aureus ST398 in pigs in Korea. Vet Microbiol. 2012; 155: 88-92.

[40] Porrero MC, Wassenaar TM, Gómez-Barrero S, Garcia M, Barcena C, Alvarez J, et al. Detection of methicillin-resistant Staphylococcus aureus in Iberian pigs. Lett Appl Microbiol. 2012; 54: 280-5.

[41] European Food Safety Authority. Analysis of the baseline survey on the prevalence of methicillin-resistant Staphylococcus aureus (MRSA) in holdings with breeding pigs, in the EU, 2008, Part A: MRSA prevalence estimates; on request from the European Commission. EFSA J. 2009; 7: e1376.

[42] Stegger M, Lindsay JA, Sørum M, Gould KA, Skov R. Genetic diversity in CC398 methicillinresistant Staphylococcus aureus isolates of different geographical origin. Clin Microbiol Infect. 2010; 16: 1017-9.

[43] Stegger M, Liu CM, Larsen J, Soldanova K, Aziz M, Contente-Cuomo T, et al. Rapid differentiation between livestock-associated and livestock-independent Staphylococcus aureus CC398 clades. PLoS ONE. 2013; 8: e79645.

[44] Valour F, Tasse J, Trouillet-Assant S, Rasigade JP, Lamy B, Chanard E, et al. Lyon Bone and Joint Infection study group. Methicillin-susceptible Staphylococcus aureus clonal complex 398: high prevalence and geographical heterogeneity in bone and joint infection and nasal carriage. Clin Microbiol Infect. 2014; 20: 772-5.

[45] Sarrou S, Liakopoulos A, Chasioti M, Foka A, Fthenakis G, Billinis C, et al. Dissemination of Methicillin-Susceptible CC398 Staphylococcus aureus strains in a rural Greek area. PLoS ONE. 2015; 10: e0122761.

[46] Cuny C, Layer F, Köck R, Werner G, Witte W. Methicillin susceptible Staphylococcus aureus (MSSA) of clonal complex CC398, t571 from infections in humans are still rare in Germany. PLoS ONE. 2013; 8: e83165.

[47] Luini M, Cremonesi P, Magro G, Bianchini V, Minozzi G, Castiglioni B, et al. Methicillinresistant Staphylococcus aureus (MRSA) is associated with low within herd prevalence of intramammary infections in dairy cows: genotyping of isolates. Vet Microbiol. 2015; 178: 270-4.

[48] Spohr M, Rau J, Friedrich A, Klittich G, Fetsch A, Guerra B, et al. Methicillin-resistant Staphylococcus aureus (MRSA) in three dairy herds in southwest Germany. Zoonoses Public Health. 2011; 58: 252-61.

[49] Tavakol M, Riekerink RG, Sampimon OC, van Hamel WJB, van Belkum A, Lam TJGM. Bovine-associated MRSA ST398 in the Netherlands. Acta Vet Scand. 2012; 1(54): 28.

[50] Silva NC, Guimarães FF, Manzi MP, Junior AF, Gomez-Sanz E, Gomez P, et al. Methicillinresistant Staphylococcus aureus of lineage ST398 as cause of mastitis in cows. Lett Appl Microbiol. 2014; 59: 665-9.

[51] Foster AP. Staphylococcal skin disease in livestock. Vet Dermatol. 2012; 23: 342-51.

[52] Meemken D, Blaha T, Tegeler R, Tenhagen BA, Guerra B, Hammerl JA, et al. Livestockassociated methicillin-resistant Staphylococcus aureus (LA-MRSA) isolated from lesions of pigs at necropsy in northwest Germany between 2004 and 2007. Zoonoses Public Health. 2010; 57: $143-8$.

[53] van der Wolf PJ, Rothkamp A, Junker K, de Neeling AJ. Staphylococcus aureus (MSSA) and MRSA (CC398) isolated from post-mortem samples from pigs. Vet Microbiol. 2012; 158: 13641. 
[54] Tristan A, Rasigade JP, Ruizendaal E, Laurent F, Bes M, Meugnier H, et al. Rise of CC398 lineage of Staphylococcus aureus among Infective endocarditis isolates revealed by two consecutive population-based studies in France. PLoS One. 2012; 7: e51172.

[55] Catry B, van Duijkeren E, Pomba MC, Greko C, Moreno MA, Pyorala S, et al. Reflection paper on MRSAin food-producing and companion animals: epidemiology and control options for human and animal health. Epidemiol Infect. 2010; 138, 626-44.

[56] Devriese LA, Hommez J. Epidemiology of methicillin-resistant Staphylococcus aureus in dairy herds. Res Vet Sci. 1975; 19: 23-7.

[57] Juhasz-Kaszanyitzky E, Janosi S, Somogyi P, Dan A, van Bloois LV, van Duijkeren E, et al. MRSA transmission between cows and humans. Emerg Infect Dis. 2007; 13: 630-2.

[58] Huijsdens XW, van Dijke BJ, Spalburg E, van Santen-Verheuvel MG, Heck MEOC, Pluister GN, et al. Community-acquired MRSA and pig-farming. Ann Clin Microbiol Antimicrob. 2006; 5: 26.

[59] de Neeling AJ, van den Broek MJ, Spalburg EC, van Santen-Verheuvel MG, Dam-Deisz WDC, Boshuizen HC, et al. High prevalence of methicillin resistant Staphylococcus aureus in pigs. Vet Microbiol. 2007; 122: 366-72.

[60] Argudín MA, Rodicio MR, Guerra B. The emerging methicillin-resistant Staphylococcus aureus ST398 clone can easily be typed using the Cfr9I SmaIneoschizomer. Lett Appl Microbiol. 2010; 50: $127-30$

[61] van Loo I, Huijsdens X, Tiemersma E, de Neeling A, van de Sande-Bruinsma N, Beaujean D, et al. Emergence of methicillin-resistant Staphylococcus aureus of animal origin in humans. Emerg Infect Dis. 2007; 13: 1834-9.

[62] van Duijkeren E, Jansen MD, Flemming SC, de Neeling H, Wagenaar JA, Schoormans AHW, et al. Methicillin-resistant Staphylococcus aureus in pigs with exudative epidermitis. Emerg Infect Dis. 2007; 13: 1408-10.

[63] Nemati M, Hermans K, Lipinska U, Denis O, Deplano A, Struelens M, et al. Antimicrobial resistance of old and recent Staphylococcus aureus isolates from poultry: first detection of livestock-associated methicillin-resistant strain ST398. Antimicrob Agents Chemother. 2008; 52: 3817-9.

[64] Mulders MN, Haenen AP, Geenen PL, Vesseur PC, Poldervaart ES, Bosch T, et al. Prevalence of livestock-associated MRSA in broiler flocks and risk factors for slaughter house personnel in the Netherlands. Epidemiol Infect. 2010; 138: 743-55.

[65] Lewis HC, Molbak K, Reese C, Aarestrup FM, Selchau M, Sørum M, et al. Pigs as source of methicillin-resistant Staphylococcus aureus CC398 infections in humans, Denmark. Emerg Infect Dis. 2008; 14: 1383-9.

[66] Guardabassi L, O’Donoghue M, Moodley A, Ho J, Boost M. Novel lineage of methicillinresistant Staphylococcus aureus, Hong Kong. Emerg Infect Dis. 2009; 15: 1998-2000.

[67] Wagenaar JA, Yue H, Pritchard J, Broekhuizen-Stins M, Huijsdens X, Mevius DJ, et al Unexpected sequence types in livestock associated methicillin-resistant Staphylococcus aureus (LA-MRSA): MRSA ST9 and a single locus variant of ST9 in pig farming in china. Vet Microbiol. 2009; 139: 405-9.

[68] Cui S, Li J, Hu C, Jin S, Li F, Guo Y, et al. Isolation and characterization of methicillin-resistant Staphylococcus aureus from swine and workers in china. J Antimicrob Chemother. 2009; 64: 680-3.

[69] Lim SK, Nam HM, Park HJ, Lee HS, Choi MJ, Jung SC, et al. Prevalence and characterization of methicillin-resistant Staphylococcus aureus in raw meat in Korea. J Microbiol Biotechnol. 2010; 20: 775-8.

[70] Ko KS, Lim SK, Jung SC, Yoon JM, Choi JY, Song JH. Sequence type 72 meticillin-resistant Staphylococcus aureus isolates from humans, raw meat and soil in South Korea. J Med Microbiol. 2011; 60: 442-5.

[71] Morgan M. Methicillin-resistant Staphylococcus aureus and animals: Zoonosis or humanosis? J Antimicrob Chemother. 2008; 62: 1181-7.

[72] Fluit AC. Livestock-associated Staphylococcus aureus. Clin Microbiol Infect. 2012; 18: 735-44. 
[73] Smith TC, Pearson N. The emergence of Staphylococcus aureus ST398. Vector Borne Zoonotic Dis. 2011; 11: 327-39.

[74] Johnson AP. Methicillin-resistant Staphylococcus aureus: the European landscape. J Antimicrob Chemother Suppl. 2011; 4: 43-8.

[75] Kock R, Mellmann A, Schaumburg F, Friedrich AW, Kipp F, Becker K. The epidemiology of methicillin-resistant Staphylococcus aureus (MRSA) in Germany. Dtsch Arztebl Int. 2011; 108: 761-7.

[76] Larsen J, Imanishi M, Hinjoy S, Tharavichitkul P, Duangsong K, Davis MF, et al. Methicillinresistant Staphylococcus aureus ST9 in pigs in Thailand. PLoS One. 2012; 7: e31245.

[77] Neela V, Zafrul AM, Mariana NS, van Belkum A, Liew YK, Rad EG. Prevalence of ST9 MRSA among Pigs and Pig Handlers in Malaysia. J Clin Microbiol. 2009; 47: 4138-40.

[78] Patchanee P, Tadee P, Arjkumpa O, Love D, Chanachai K, Alter T, et al. Occurrence and characterization of livestock-associated methicillin-resistant Staphylococcus aureus in pig industries of northern Thailand. J Vet Sci. 2014; 15: 529-36.

[79] Fang HW, Chiang PH, Huang YC. Livestock-associated methicillin-resistant Staphylococcus aureus ST9 in pigs and related personnel in Taiwan. PLoS One. 2014; 9: e88826.

[80] Wendlandt S, Kadlec K, Fessler AT, Monecke S, Ehricht R, van de Giessen AW, et al. Resistance phenotypes and genotypes of methicillin-resistant Staphylococcus aureus isolates from broiler chickens at slaughter and abattoir workers. J Antimicrob Chemother. 2013; 68: 2458-63.

[81] Buyukcangaz E, Velasco V, Sherwood JS, Stepan RM, Koslofsky RJ, Logue CM. Molecular typing of Staphylococcus aureus and methicillin-resistant Staphylococcus aureus (MRSA) isolated from animals and retail meat in North Dakota, United States. Foodborne Pathog Dis. 2013; 10: 608-17.

[82] Graveland H, Duim B, van Duijkeren E, Heederik D, Wagenaar JA. Livestock-associated methicillin-resistant Staphylococcus aureus in animals and humans. Int J Med Microbiol. 2011; 301: 630-4.

[83] Lowder BV, Guinane CM, Ben Zakour NL, Weinert LA, Conway-Morris A, Cartwright RA, et al. Recent humanto-poultry host jump, adaptation, and pandemic spread of Staphylococcus aureus. Proc Natl Acad Sci USA. 2009; 106: 19545-50.

[84] Schulz J, Friese A, Klees S, Tenhagen BA, Fetsch A, Rosler U, et al. Longitudinal study of the contamination of air and of soil surfaces in the vicinity of pig barns by livestock-associated methicillin-resistant Staphylococcus aureus. Appl Environ Microbiol. 2012; 78: 5666-71.

[85] Bos ME, Verstappen KM, van Cleef BA, Dohmen W, Dorado-Garcia A, Graveland H, et al. Transmission through air as a possible route of exposure for MRSA. J Expo Sci Environ Epidemiol. 2014; 17.

[86] Cuny C, Nathaus R, Layer F, Strommenger B, Altmann D, Witte W. Nasal colonization of humans with methicillin-resistant Staphylococcus aureus (MRSA) CC398 with and without exposure to pigs. PLoS ONE. 2009; 4: e6800.

[87] van den Broek IVF, van Cleef BAG, Haenen A, Broens EM, van der Wolf PJ, van den Broek MJM, et al. Methicillin-resistant Staphylococcus aureus in people living and working in pig farms. Epidemiol Infect. 2009; 137: 700-8.

[88] Graveland H, Wagenaar JA, Bergs K, Heesterbeek H, Heederik D. Persistence of livestock associated MRSA CC398 in humans is dependent on intensity of animal contact. PLoS ONE. 2011; 6: e16830.

[89] van Cleef BAGL, Graveland H, Haenen APJ, van de Giessen AW, Heederik D, Wagenaar JA, et al. Persistence of livestock-associated methicillin-resistant Staphylococcus aureus in field workers after short-term occupational exposure to pigs and veal calves. J Clin Microbiol. 2011; 49: $1030-3$.

[90] Köck R, Loth B, Köksal M, Schulte-Wulwer J, Harlizius J, Friedrich AW. Persistence of nasal colonization with livestock-associated methicillin-resistant Staphylococcus aureus in pig farmers after holidays from pig exposure. Appl Environ Microbiol. 2012; 78: 4046-7. 
[91] Garcia-Graells C, van Cleef BAGL, Larsen J, Denis O, Skov R, Voss A. Dynamic of livestockassociated methicillin-resistant Staphylococcus aureus CC398 in pig farm households: A pilot study. PLoS ONE. 2013; 8: e65512.

[92] van Cleef BAGL, van Benthem BHB, Verkade EJM, van Rijen MML, Kluytmants-van den Bergh MFQ, Graveland H, et al. Livestock-associated MRSA in household members of pig farmers: Transmission and dynamics of carriage, a prospective cohort study. PLoS ONE. 2015; 10: e0127190.

[93] Dorado-García A, Dohmen W, Bos MEH, Verstappen KM, Houben M, Wagenaar JA, et al. Dose-response relationship between antimicrobial drugs and livestock-associated MRSA in pig farming. Emerg Infect Dis. 2015: 21: 950-9.

[94] van Cleef BA, Broens EM, Voss A. High prevalence of nasal MRSA carriage in slaughterhouse workers in contact with live pigs in The Netherlands. Epidemiol Infect. 2010; 138: 756-63.

[95] Hermes J, Witte W, Cuny C, Kleinkauf N, Jansen A, Eckmanns T. Prevalence of MRSA nasal colonization over times in veterinarians and their household contacts in Germany. Intern J Med Microbiol. 2012; 302: 146.

[96] Garcia-Graells C, Antoine J, Larsen J, Catry B, Skov R, Denis O. Livestock veterinarians at high risk of acquiring methicillin-resistant Staphylococcus aureus ST398. Epidemiol Infect. 2012; 140: 383-9.

[97] Verkade E, Kluytmans-van den Bergh M, van Benthem B, van Cleef B, van Rijen M, Bosch T, et al. Transmission of methicillin-resistant Staphylococcus aureus CC398 from livestock veterinarians to their household members. PLoS ONE. 2014; 9: e100823.

[98] Bosch T, Verkade E, van Luit M, Landman F, Kluytmants J, Schouls LM. Transmission and persistence of livestock-associated methicillin-resistant Staphylococcus aureus among veterinarians and their household members. Appl Environ Microbiol. 2015; 81: 124-9.

[99] Cuny C, Friedrich AW, Witte W. Absence of livestock-associated methicillin-resistant Staphylococcus aureus clonal complex CC398 as a nasal colonizer of pigs raised in an alternative system. Appl Environ Microbiol. 2012; 78: 1296-7.

[100] van de Vijver LP, Tulinski P, Bondt N, Mevius D, Verwer C. Prevalence and molecular characteristics of methicillin-resistant Staphylococcus aureus (MRSA) in organic pig herds in The Netherlands. Zoonoses Public Health. 2014; 61: 338-45.

[101] Köck R, Schaumburg F, Mellmann A, Koksal M, Jurke A, Becker K, et al. Livestock-associated methicillin-resistant Staphylococcus aureus (MRSA) as causes of human infection and colonization in Germany. PLoS ONE. 2013; 8: e55040.

[102] Feingold BJ, Silbergeld EK, Curriero FC, van Cleef BAGL, Heck MEOC, Kluytmans JAJW. Livestock density as risk factor for livestock-associated methicillin-resistant Staphylococcus aureus, the Netherlands. Emerg Infect Dis. 2012; 18: 1841-9.

[103] Friese A, Schulz J, Laube H, von Salviati C, Hartung J, Roesler U. Faecal occurrence and emissions of livestock-associated methicillin-resistant Staphylococcus aureus (LA-MRSA) and ESBL/AmpC-producing E. coli from animal farms in Germany. Berl Munch Tierarztl Wochenschr. 2013; 126: 175-80.

[104] Friese A, Schulz J, Zimmermann K, Tenhagen BA, Fetsch A, Hartung J, et al. Occurrence of livestock-associated methicillin-resistant Staphylococcus aureus in Turkey and broiler barns and contamination of air and soil surfaces in their vicinity. Appl Environ Microbiol. 2013; 79: 275966.

[105] Loncaric I, Stalder GL, Mehinagic K, Rosengarten R, Hoelzl F, Knauer F, et al. Comparison of ESBL- and AmpC producing Enterobacteriaceae and methicillin-resistant Staphylococcus aureus (MRSA) isolated from migratory and resident population of rooks (Corvus frugilegus) in Austria. PLoS ONE. 2013; 8: e84048.

[106] Bisdorff B, Scholhölter JL, Claußen K, Pulz M, Nowak D, Radon K. MRSA-ST398 in livestock farmers and neighbouring residents in a rural area in Germany. Epidemiol Infect. 2012; 140: 1800-8.

[107] Casey JA, Curriero FC, Cosgrove SE, Nachman KE, Schwartz BS. High-density livestock operations, crop field application of manure, and risk of community-associated methicillin- 
resistant Staphylococcus aureus infection in Pennsylvania. JAMA Intern Med. 2013; 173: 198090.

[108] Idelevich EA, Lanckohr C, Horn D, Wieler LH, Becker K, Kock R. Multidrug-resistant bacteria in Germany: The impact of sources outside healthcare facilities. Bundesgesundheitsblatt Gesundheitsforschung Gesundheitsschutz. 2015; 59(1): 113-23.

[109] Benito D, Lozano C, Rezusta A, Ferrer I, Vasquez MA, Ceballos S, et al. Characterization of tetracycline and methicillin resistant Staphylococcus aureus strains in a Spanish hospital: Is livestock-contact a risk factor in infections caused by MRSA CC398? Int J Med Microbiol. 2014; 304: 1226-32.

[110] Deiters C, Günnewig V, Friedrich AW, Mellmann A, Kock R. Are cases of Methicillin-resistant Staphylococcus aureus clonal complex (CC) 398 among humans still livestock-associated? Int J Med Microbiol. 2015; 305: 110-3.

[111] van Rijen MML, Kluytmans-van den Bergh MFQ, Verkade EJM, ten Ham PBG, Feingold BJ, Kluytmants JAJW. Lifestyle-associated risk factors for community-acquired methicillinresistant Staphylococcus aureus carriage in the Netherlands: An exploratory hospital-based casecontrol Study. PLoS ONE. 2013; 8: e65594.

[112] Layer F, Cuny C, Strommenger B, Werner G, Witte W. Aktuelle Daten und Trends zu Methicillin-resistenten Staphylococcus aureus (MRSA). Bundesgesundheitsbl. 2012: 55; 1377 86.

[113] Witte W, Strommenger B, Stanek C, Cuny C. Methicillin-resistant Staphylococcus aureus ST398 in humans and animals, Central Europe. Emerg Infect Dis. 2007; 13: 255-8.

[114] Juretzek M, Armengol-Porta A, Bühling R, Haubold M, Pohle F, Schwab WB. Epidemiology of methicillin-resistant Staphylococcus aureus at hospital admission in South Brandenburg, Germany. Intern J Med Microbiol. 2011; 301: 100.

[115] Cuny C, Layer F, Werner G, Harmsen D, Daniels-Haardt I, Jurke A, et al. State-wide surveillance of antibiotic resistance patterns and spa types of methicillin-resistant Staphylococcus aureus from blood cultures in North Rhine-Westphalia, 2011-2013. Clin Microbiol Infect. 2015; 21: $750-7$.

[116] van de Sande-Bruinsma N, Leverstein van Hall MA, Janssen M, Nagtzaam N, Leenders S, de Greef SC, et al. Impact of livestock-associated MRSA in a hospital setting. Antimicrob Res Infect Control. 2015; 4.

[117] Wulf MWH, Markestein A, van der Linden FT, Voss A, Klaassen C, Verduin CM. First outbreak of methicillin-resistant Staphylococcus aureus ST398 in a Dutch hospital in June 2007. Euro Surveill. 2008; 13: e8051.

[118] Wassenberg MWM, Bootsma MCJ, Troelstra A, Kluytmants JAJW, Bonten MJM. Transmissibility of livestock-associated methicillin-resistant Staphylococcus aureus (ST398) in Dutch hospitals. Clin Microbiol Infect. 2011; 17: 316-9.

[119] Ward MJ, Gibbons CL, McAdam PR, van Bunnik BAD, Girvan EK, Edwards GF, et al. TimeScaled Evolutionary Analysis of the Transmission and Antibiotic Resistance Dynamics of Staphylococcus aureus Clonal Complex 398. Appl Environ Microbiol. 2014; 80: 7275-82.

[120] Witte W, Cuny C. Emergence and spread of cfr-mediated multiresistance in staphylococci: An interdisciplinary challenge. Future Microbiol. 2011; 6: 925-31.

[121] Wendlandt S, Shen J, Kadlec K, Wang Y, Li B, Zhang WJ, et al. Multidrug resistance genes in staphylococci from animals that confer resistance to critically and highly important antimicrobial agents in human medicine. Trends Microbiol. 2015; 23: 44-54.

[122] Kehrenberg C, Schwarz S. Distribution of florfenicol resistance genes fexA and cfr among chloramphenicol-resistant Staphylococcus isolates. Antimicrob Agents Chemother. 2006; 50: 1156-63.

[123] Zeng ZL, Wei HK, Wang J, Lin DC, Liu XQ, Liu JH. High prevalence of Cfr-producing Staphylococcus species in retail meat in Guangzhou, China. BMC Microbiol. 2014; 14.

[124] Mendes RE, Flamm RK, Hogan PA, Ross JE, Jones RN. Summary of linezolid activity and resistance mechanisms detected during the 2012 LEADER surveillance program for the United States. Antimicrob Agents Chemother. 2014; 58: 1243-7. 
[125] Bender J, Strommenger B, Steglich M, Zimmermann O, Fenner I, Lensing C, et al. Linezolid resistance in clinical isolates of Staphylococcus epidermidis from German hospitals and characterization of two cfr-carrying plasmids. J Antimicrob Chemother. 2015; 70: 1630-8.

[126] Kehrenberg C, Cuny C, Strommenger B, Schwarz S, Witte W. Methicillin-resistant and susceptible Staphylococcus aureus strains of clonal lineages ST398 and ST9 from swine carry the multidrug resistance gene cfr. Antimicrob Agents Chemother. 2009; 53: 779-81.

[127] Shen J, Wang Y, Schwarz S. Presence and dissemination of the multiresistance gene cfr in Grampositive and Gram-negative bacteria. J Antimicrob Chemother. 2013; 68: 1697-706.

[128] Mendes RE, Deshpande LM, Jones RN. Linezolid update: Stable in vitro activity following more than a decade of clinical use and summary of associated resistance mechanisms. Drug Res Update. 2014; 17: 1-12.

[129] Weinstein MP. Blood culture contamination: Persisting problems and partial progress. J Clin Microbiol. 2003; 41: 2275-8.

[130] Hall KK, Lyman JA. Updated review of blood culture contamination. Clin Microbiol Rev. 2006; 19: 788-802.

[131] Gentry CA, Rodvold KA, Novak RM, Hershow RC, Naderer OJ. Retrospective evaluation of therapies for Staphylococcus aureus endocarditis. Pharmacotherapy. 1997; 17: 990-7.

[132] Lodise TP, McKinnon PS, Levine DP, Rybak MJ. Impact of empirical-therapy selection on outcomes of intravenous drug users with infective endocarditis caused by methicillinsusceptible Staphylococcus aureus. Antimicrob Agents Chemother. 2007; 51: 3731-3.

[133] Brown J, Paladino JA. Impact of rapid methicillin-resistant Staphylococcus aureus polymerase chain reaction testing on mortality and cost effectiveness in hospitalized patients with bacteraemia: A decision model. Pharmacoeconomics. 2010; 28: 567-75.

[134] Schweizer ML, Furuno JP, Harris AD, Johnson JK, Shardell MD, McGregor JC, et al. Comparative effectiveness of nafcillin or cefazolin versus vancomycin in methicillinsusceptible Staphylococcus aureus bacteremia. BMC Infect Dis. 2011; 11: 279.

[135] Polisena J, Chen S, Cimon K, McGill S, Forward K, Gardam M. Clinical effectiveness of rapid tests for methicillin resistant Staphylococcus aureus (MRSA) in hospitalized patients: A systematic review. BMC Infect Dis. 2011; 11: 336.

[136] Bauer KA, West JE, Balada-Llasat JM, Pancholi P, Stevenson KB, Goff DA. An antimicrobial stewardship program's impact with rapid polymerase chain reaction methicillinresistant Staphylococcus aureus / Staphylococcus aureus blood culture test in patients with Staphylococcus aureus bacteremia. Clin Infect Dis. 2010; 51: 1074-80.

[137] Parta M, Goebel M, Thomas J, Matloobi M, Stager C, Musher DM. Impact of an assay that enables rapid determination of Staphylococcus species and their drug susceptibility on the treatment of patients with positive blood culture results. Infect Control Hosp Epidemiol. 2010; 31: 1043-8.

[138] Turlej A, Hryniewicz W, Empel J. Staphylococcal cassette chromosome mec (SCCmec) classification and typing methods: An overview. Pol J Microbiol. 2011; 60: 95-103.

[139] International Working Group on the Classification of Staphylococcal Cassette Chromosome Elements (IWG-SCC). Classification of staphylococcal cassette chromosome mec (SCCmec): Guidelines for reporting novel SCCmec elements. Antimicrob Agents Chemother. 2009; 53: 4961-7.

[140] Brakstad OG, Maeland JA, Chesneau O. Comparison of tests designed to identify Staphylococcus aureus thermostable nuclease. APMIS. 1995; 103: 219-24.

[141] Kim JU, Cha CH, An HK, Lee HJ, Kim MN. Multiplex real-time PCR assay for detection of methicillin-resistant Staphylococcus aureus (MRSA) strains suitable in regions of high MRSA endemicity. J Clin Microbiol. 2013; 51: 1008-13.

[142] Kobayashi N, Wu H, Kojima K, Taniguchi K, Urasawa S, Uehara N, et al. Detection of mecA, $f e m \mathrm{~A}$, and $f e m \mathrm{~B}$ genes in clinical strains of staphylococci using polymerase chain reaction. Epidemiol Infect. 1994; 113: 259-66.

[143] Sullivan KV, Turner NN, Roundtree SS, Young S, Brock-Haag CA, Lacey D, et al. Rapid detection of Gram-positive organisms by use of the Verigene Gram-positive blood culture 
nucleic acid test and the BacT/Alert pediatric FAN system in a multicenter pediatric evaluation. J Clin Microbiol. 2013; 51: 3579-84.

[144] Cuny C, Friedrich A, Kozytska S, Layer F, Nubel U, Ohlsen K, et al. Emergence of methicillinresistant Staphylococcus aureus (MRSA) in different animal species. Int J Med Microbiol. 2010; 300: 109-17.

[145] Kluytmans JA. Methicillin-resistant Staphylococcus aureus in food products: cause for concern or case for complacency? Clin Microbiol Infect. 2010; 16: 11-15.

[146] van Rijen MM, van Keulen PH, Kluytmans JA. Increase in a Dutch hospital of methicillinresistant Staphylococcus aureus related to animal farming. Clin Infect Dis. 2008; 46: 261-3.

[147] Wassenberg MW, Bonten MJ. The Dutch MRSA policy can and should be different. Ned Tijdschr Geneeskd. 2010; 154: e2575.

[148] Grubb WB. Genetics of MRSA. Rev Med Microbiol. 1998; 9: 153-62.

[149] Chambers HF, DeLeo FR. Waves of resistance: Staphylococcus aureus in the antibiotic era. Nat Rev. 2009; 7: 629-41.

[150] Chang S, Sievert DM, Hageman JC, Boulton ML, Tenover FC, Downes FP, et al. Infection with vancomycin-resistant Staphylococcus aureus containing the vanA resistance gene. N Engl J Med. 2003; 348: 1342-7.

[151] Weigel LM, Clewell DB, Gill SR, Clark NC, McDougal LK, Flannagan SE, et al. Genetic analysis of a high-level vancomycin-resistant isolate of Staphylococcus aureus. Science. 2003; 302: $1569-71$.

[152] Roca I, Akova M, Baquero F, Carlet J, Cavaleri M, Soenen S, et al. The global threat of antimicrobial resistance: science for intervention. New Microbes New Infect. 2015; 6: 22-9.

[153] Siegel JD, Rhinehart E, Jackson M, Chiarello L, The healthcare infection control practices advisory committee. Management of multidrug-resistant organisms in healthcare settings. Am J Infect Control. 2007; 35: 165-93.

[154]Farbman L, Avni T, Rubinovitch B, Leibovici L, Paul M. Cost-benefit of infection control interventions targeting methicillin-resistant Staphylococcus aureus in hospitals: systematic review. Clin Microbiol Infect. 2013; 19: 582-93. 